\title{
An Exploration of Pedagogic Practices of Expressive Arts Teachers in Malawi Primary Schools
}

\author{
Grames Chirwa (PhD)
}

University of Johannesburg;

Email: grameschirwa@yahoo.co.uk

\section{Devika Naidoo (PhD)}

University of Johannesburg; Email:devikan@uj.ac.za

Doi:10.5901/mjss.2014.v5n16p261

\begin{abstract}
The objective of curriculum reform is to improve current practices. To improve the quality of education in Malawi, the national government in 2001 embarked on curriculum reform and adopted an Outcomes Based curriculum in 2007. Not much is known about the enactment of the new policy in classroom practices of teachers. The purpose of this study was to investigate the enactment of Expressive Arts, its theme-based design and content, facilitative pedagogy and continuous assessment in a selection of six state primary schools - three urban and three rural in Zomba district where teachers were first trained to teach Expressive Arts. The study was framed by the theory of Illuminative evaluation (Parlett and Hamilton, 1976) and Productive Pedagogies (Lingard, et al, 2001). Following a qualitative research design, data were collected through observation and postobservation interviews. Data analysis showed limited productive pedagogies in most lessons. The majority of lessons were characterised by lower intellectual quality. For example, didactic teaching was very much the order of the day and little opportunity, if any, was provided for reflection and discussion with the pupils. The overall findings is that the enacted curriculum gave students limited opportunities for the acquisition of knowledge and development of skills, values and attitudes required for them to actively participate in the changing Malawian context and to be able to compete successfully in other contexts. It appears that dominant pedagogic practices in the Expressive Arts classroom serve to position learners in parochial orientations and issues. There was an obvious disjuncture between the intended curriculum and enacted curriculum.
\end{abstract}

Keywords: Expressive Arts, Illuminative evaluation, Productive Pedagogies, instructional system, learning milieu, intended curriculum, enacted curriculum.

\section{Introduction}

To improve the quality of education in Malawi, the national government embarked on curriculum reform in 2001. The Primary Curriculum and Assessment Reform (PCAR) implemented in 2007 intended to improve the quality of education in the country by addressing the weaknesses of the previous curriculum. The previous curriculum was overloaded with content due to a wide range of subjects and teaching and learning was examination rather than learner oriented (Khomani, 2003).

Expressive Arts is one of the nine learning areas in the 2007 national curriculum. It is an integrated curriculum using themes such as body movements, conveying cultural messages, multi-cultural performances and dances to integrate across multiple subject disciplines including Creative Arts, Physical Education, Music, Drama and Needlecraft. Expressive Arts differs from its predecessors in that they were designed around objectives rather than outcomes, emphasised content rather than skills, advocated didactic rather than facilitative pedagogies and assessed students through formal summative examinations rather than continuous assessment. Through PCAR, the government aimed to shift education from content-based to outcomes-based education similar to Curriculum 2005 (C2005) in South Africa.

The adoption of an OBE curriculum in Malawi arose from regional influences, particularly the first Southern African Development Community (SADC) Protocol on Education and Training adopted in 1997. The Protocol influenced the formulation of a new feature in South African education: an integrated qualifications framework (Chisholm, 2005). By 2004 a number of SADC countries including Malawi formulated a curriculum with a strong vocational and training slant: an Outcomes Based Curriculum. The design features of the PCAR have been influenced by South Africa's Curriculum 


\section{5 (C2005).}

Following the introduction of the new national curriculum in Malawi in 2007 and its implementation over the past two years in schools across the nation, the purpose of this research was to evaluate the extent to which the Expressive Arts curriculum is being implemented as intended. The study was thus aimed to uncover how the Expressive Arts curriculum is enacted in diverse classrooms in primary schools in Malawi.

The significance of this study lies in the fact that although literature in Malawi indicates that teachers in the primary school sector face enormous constraints, Mhango (2010) observed that there are not many studies that investigated, in a crucial way, how such constraints impact on teachers' classroom practices in implementing a curriculum innovation. In this connection, Croft (2002), who studied the use of songs in English lessons of lower classes in primary schools in Malawi, argued that most of donor-funded research in the country focussed on factors affecting the quality of education rather than classroom practices. She therefore recommended a more critical investigation of how teachers implement the school curricula. Owing to the limited number of studies in this area, this study aimed at learning how teachers enacted the new Expressive Arts curriculum to meet the state's goal of improving the quality of education in Malawi.

\section{Conceptual Framework}

As it has been stated earlier on, the purpose of this study was to evaluate the teaching of Expressive Arts two years into the implementation of the national innovation in Malawi.

Evaluation means comparing to a normative understanding of 'good' practice. There are a variety of models of evaluation that are useful for different purposes. Amongst the various models of evaluation, Illuminative evaluation (Parlett and Hamilton 1976) provided a promising macro-framework for evaluating the intended Expressive Arts curriculum as the government in Malawi designed and planned it to be taught and the actual way in which teachers are teaching it in the primary schools. The Illuminative approach has the ability to take into account the teachers' perspectives of the curriculum as they implement it and to compare the intended to the enacted curriculum.

Two key components of Illuminative Evaluation are the Instructional System and the Learning Milieu. The Instructional System refers to what has been planned and written up in documents to guide teaching and learning. These documents include syllabuses, teachers' and pupils' books, and all other relevant teaching and learning materials. The 'learning milieu', refers to what teachers and learners actually do in classrooms.

Illuminative evaluation thus enables understanding of the 'gap' or 'fit' between the Instructional System and the Learning Milieu. In using Illuminative evaluation in the study, the difference or 'gap' between the terms 'instructional system' and the 'learning milieu' made it possible to ascertain whether the enacted curriculum is meeting the goals of the instructional system and whether Malawi ought to still follow the OBE route. However, to evaluate, one needs a yardstick for comparison. Therefore Productive Pedagogies (Lingard, et al, 2001) was used to complement Illuminative evaluation as a yardstick to which the enacted curriculum was compared.

The notion of Productive Pedagogies emerged from the School Reform Longitudinal Study (SRLS) which was conducted in Queensland Schools, Australia between 1998 to 2001 (Zohir, et al, 2010). The theory was developed by Lingard, et al (2001). The theory emerged as a research tool for exploring classroom practices that promote a high quality education for all students, regardless of background. The Productive Pedagogies theory consists of four dimensions namely high intellectual quality, connectedness to the world beyond the classroom, supportive classroom environment and engagement with difference. The four dimensions that have been broken down into a range of indicators. For this paper, the first dimension of high intellectual quality and its indicators provided the analytical criteria for evaluating a curriculum which was introduced to improve the quality of education in Malawi. The first indicator of high intellectual quality is evidence of higher order thinking-such as critical analysis, synthesis, explaining and hypothesizing. The second indicator: deep knowledge refers to whether key ideas and concepts of the discipline or field are being mediated and to conceptual progression such as increasing number, depth and interconnections between concepts. The third indicator deep understanding refers to whether responses show understanding. The fourth indicator: knowledge as problematic refers to whether multiple perspectives are acknowledged. The fifth indicator substantive conversation refers to evidence of extended talk between students and between students and teachers. The sixth indicator metalanguage refers to awareness of one's language, specific technical vocabulary and terms, about meaning and ideology in language used.

Previous classroom studies indicate that classrooms high in intellectual quality help students to perform well academically (Boaler, 1997; Hayes et al., 2006). For this reason, Productive Pedagogies was adopted as a suitable lens for evaluating the new curriculum in Malawi. A major reason that made Productive Pedagogies theory significant to this study is that this approach seemed to offer a useful lens for understanding how teachers develop a suitable level of intellectual quality for learners in the classroom. 


\section{Data Collection}

This paper arose from a larger doctoral research project focused on studying the pedagogic practices of Expressive Arts teachers in Standards 7 and 8 classrooms, through the lens of Illuminative Evaluation and Lingard's, et al (2001) concept of Productive Pedagogies.

This research used a triangulation of data collection procedures involving various sources of data that included documentary review, a questionnaire, lesson observations and post observation interviews as principles of illuminative evaluation to investigate the 'instructional system' and the 'learning milieu'. The primary data source for this study were the classroom observations.

Two techniques were used to record data. A digital recorder was used to audio tape teachers and learners voice and field notes were made to capture what was done in the classroom. Key practices in the lessons were probed in the interviews. The audio tapes of lessons, transcribed by the researcher, generated more than three hundred pages of transcripts. The 71 lesson transcripts were divided into episodes and each episode was scrutinised for evidence of the indicators of high intellectual quality.

The indicators of high intellectual quality were deductively applied to the data. The indicators illuminated the lessons in which high intellectual quality was evident; specific teachers whose lessons illustrated high intellectual quality; variations in intellectual quality within lessons; and variations in intellectual quality in urban and rural schools.

\section{Participants}

The data was collected in six schools over a period of five months, from January, 2010 to May, 2010. In all, twelve Expressive Arts teachers drawn from the six state schools in Zomba were studied. The teachers represented Standards 7 and 8 in a school. All the teachers in the study were qualified. Their teaching experiences ranged from 5 to 20 years. Their ages ranged from 34 to 52 years. Seven of the teachers in the study were females and five were males. All 7 teachers were trained in the normal training program of the teaching of Expressive Arts. The school and teacher samples used in the study are summarised in tables 1 and 2 below:

Table 1: Summary of study schools

\begin{tabular}{|l|c|c|c|c|c|c|}
\hline \multicolumn{1}{|c|}{ School } & A & B & C & D & E & F \\
\hline Type & Rural & Urban & Rural & Urban & Rural & Urban \\
\hline Roll & 1333 & 725 & 761 & 1156 & 604 & 2743 \\
\hline Teachers & 21 & 25 & 16 & 34 & 8 & 61 \\
\hline Teacher- pupil ratio & $1: 63$ & $1: 29$ & $1: 95$ & $1: 34$ & $1: 75$ & $1: 45$ \\
\hline Number of teachers participants & 2 & 2 & 2 & 2 & 2 & 2 \\
\hline
\end{tabular}

Table 2: Teachers of Expressive Arts biographical data

\begin{tabular}{|c|c|c|c|c|c|c|c|c|}
\hline & Gender & Age & $\begin{array}{c}\text { Teaching } \\
\text { Standard }\end{array}$ & $\begin{array}{c}\text { Academic } \\
\text { qualification }\end{array}$ & $\begin{array}{c}\text { Education } \\
\text { qualification }\end{array}$ & $\begin{array}{c}\text { Teaching } \\
\text { Experience }\end{array}$ & $\begin{array}{c}\text { Experience in } \\
\text { Expressive Arts }\end{array}$ & School \\
\hline 1 & Female & 45 & 8 & MSCE & T2 & 20 years & 1 year & $\mathrm{F}$ \\
2 & Female & 40 & 7 & MSCE & T2 & 14 years & 1 year & A \\
3 & Female & 34 & 8 & MSCE & T2 & 13 years & 1 year & B \\
4 & Female & 35 & 7 & MSCE & T2 & 10 years & 2 years & B \\
5 & Female & 39 & 7 & JCE & T3 & 16 years & 1 year & $\mathrm{F}$ \\
6 & Female & 40 & 8 & MSCE & T2 & 17 years & 2 years & A \\
7 & Female & 37 & 7 & MSCE & T2 & 14 years & 2 years & D \\
8 & Male & 38 & 7 & MSCE & T2 & 16 years & 2 years & C \\
9 & Male & 52 & 7 & MSCE & T2 & 10 years & 2 years & E \\
10 & Male & 36 & 8 & MSCE & T2 & 14 years & 2 years & E \\
11 & Female & 40 & 8 & MSCE & T2 & 15 years & 2 years & D \\
12 & Male & 42 & 8 & MSCE & T2 & 20 years & 2 years & C \\
\hline
\end{tabular}




\section{Findings}

\subsection{The Intellectual Quality of lessons}

Although a few lessons or parts of lessons contained elements of higher intellectual quality, the majority of lessons were characterised by lower intellectual quality. Didactic teaching was very much the order of the day and little opportunity, if any, was provided for reflection and discussion with the pupils. For this paper, relevant excerpts from the transcripts of the 71 lessons observed in this study have been cited to illustrate the lower intellectual quality of lessons. Of the 71 lessons observed in the study, $61 \%$ (43 lessons out of 71 ) were of low intellectual quality.

\subsubsection{Higher order thinking}

Data analysis showed that there were minimal possibilities for higher order thinking by the learners, as most of the Expressive Arts teachers did not encourage the learners to think deeply nor involve them actively during the teaching and learning process. The learners either passively received information from the teachers or recited what the teachers told them. Below, an episode of an Expressive Arts lesson in a rural school that illustrates lower order thinking is examined.

Teacher: In today's lesson, we are going to look at sounds used to convey messages. In your communities, if you hear different sounds, you should be able to know that a certain type of sound conveys a certain type of message. Can you now be in your usual groups and discuss sounds which are produced in your communities which can be used to convey messages.

(The learners made four groups with one group consisting of boys only. I listened to the discussion of this group. There was very little discussion going on in the group. The only discussion taking place amongst the learners in the group was that one learner said, "Drum is produce dancing," and another learner said, "whistle is producing wedding". The teacher then called group leaders to write on the chalkboard what they had discussed in their groups) 10:45: a.m.

Teacher: Group leaders, can you come upfront and write on the chalkboard what you have discussed in your groups.

(Representatives of the groups wrote the following on the chalkboard).

Group 1: drum- dances, ambulance- to take patients.

Group 2: drum - dancing, whisle-'nyau'.

Group 3: drum is produce dancing.

Group 4: Cock is telling time.

The discourse in the above excerpt showed that learners are involved in low-order thinking. For example, the discussion among the learners in their groups and their responses presented to the class, such as, 'drum is produce dancing'[sic], 'drum-dances', 'ambulance-to take patients', and 'cock is telling time', shows very little evidence of higherorder thinking in the learners. The low-level questions which the teacher asked did not encourage the learners to think deeper and involve them actively in the teaching and learning process. The above excerpt illustrates the general practice that teachers simply transmitted information to learners and that learners received information passively from their teacher.

While higher-order thinking was weakly evident in most of the lessons, some of the lessons observed showed some possibilities for higher-order thinking. Of the lessons observed, 39 percent (28 lessons out of 71 ) showed possibilities for higher-order thinking. These 28 lessons had 14 episodes of higher-order thinking. Below, an episode illustrating the opportunity for higher order thinking in the lessons is examined.

The lesson began at 8:00 a.m. There were 27 children present that day. As part of the introduction of the day's Expressive Arts lesson, the teacher formally greeted the learners and began the lesson as follows:

Teacher: Yesterday, we discussed about the roles of the leaders. We talked about the characteristics of a leader and their leadership styles. Is there anybody who can tell us what a leader is?

Learner: A leader is a person who leads other people.

Teacher: We also talked about the leadership styles. Can you list the leadership styles which we discussed?

Learner: Majority rules.

Teacher: Is that a leadership style?

Learner: Dictatorship 


\begin{abstract}
Teacher: That is very good. Sometimes we say what? Learner: Autocratic

Teacher: Do we have characteristics of autocratic leadership? Or dictatorship leadership style? Just give me one of the characteristics. All these leadership styles have their own characteristics. What about autocratic?

Learner: Only the leader's voice count. What the leader says is the only thing which can be done. Nobody can say or can give ideas. No other ideas are welcome. Only the leader says this and so the people do whatever their leader tells them to do. The people just follow what the leader is telling them to do.
\end{abstract}

The above excerpt illustrates greater possibility for higher-order thinking. Learners were responding to their teachers' questions. In the episode, the teacher asked open-ended questions which required learners to manipulate information and ideas to respond to the teacher's question, "Do we have characteristics of autocratic leadership? Or dictatorship leadership style? Just give me one of the characteristics. All these leadership styles have their own characteristics. What about autocratic?"

In response to the teacher's question, the learner responded, "Only the leader's voice count. What the leader says is the only thing which can be done. Nobody can say or can give ideas. No other ideas are welcome. Only the leader says this and so the people do whatever their leader tells them to do. The people just follow what the leader is telling them to do." This response illustrates higher-order thinking by a learner. The learner gave a well thought-out answer which is a synthesis of facts and ideas in response to the teacher's question. The learner is not giving just a one-word answer to the teacher's question.

\title{
5.1.2 Deep knowledge
}

The lessons showed a range of deep to shallow knowledge. Sometimes the knowledge discourses were deep and focused on well structured classifications of concepts, while for the rest of the time, very simplistic, unstructured, community, local and everyday discourses were being discussed.

Data analysis revealed that $30 \%$ (21 out of 71) of the lessons were characterised by Deep knowledge, 45 episodes in 21 lessons were characterised by Deep knowledge.

Below, an episode illustrating deep knowledge in the lessons is examined.

Teacher: We have seen the leaders of different styles. The leaders who practice democracy and the leaders who are dictators. The different types of leaders have different successes and challenges. Challenges is the same as problems. The leaders meet successes and challenges. Atsogoleri aja amakumana ndi zinthu zovuta ndi zina zosavuta. Akakhala mumidzi muja amakumana ndi zina zovuta kuti ayendetse utsogoleri wao. Zimene zimakanikitsa atsogoleri kuti ayendetse bwino utsogoleri wao ndi ma challenges (translated as: those leaders in your villages for example meet some issues which they are able to resolve without many difficulties. Those are what we call successes. However those leaders again meet some issues brought by their villagers which are difficult for them to resolve. Those issues are what we call challenges). Challenges are some of the things which they are able to resolve. Zimene zimakanika zija ndiye ma challenges (translated as: those issues which they fail to resolve is what we call challenges. So we want to look at those things.

At 8: 21 a.m, I sat with one group which was composed of four girls and one boy. The learners wrote down the following facts; when leaders face challenges, they should not give up but they should find solutions to their challenges. The leader should delegate. One girl learner told classmates at her group, 'leaders should not give up when they find problems but they should face up the challenges.' Another learner told fellow classmates that, 'the leader should practice justice, the leader should encourage people to work together, the leader should encourage people to work in unity, the leader should practice justice, the leader should encourage unity, the leader should not take any sides.'

The above excerpt shows that Deep knowledge is being covered in the lessons for four reasons. Firstly, there is greater analysis and classification of leadership styles. For example, the teacher developed a taxonomy that reflected better the conceptual structure of leadership styles - dictatorship and democratic. Secondly the teacher made use of three analytical classifications of what he was going to discuss with learners about leadership styles. These analytical classifications are successes of leaders, problems or challenges of leaders and solutions to the challenges which leaders face. Thirdly, key ideas and concepts of 'leadership styles' is being analyzed and explained. For example, the teacher explains at length the meaning of the concept 'challenges' by using everyday terms such as 'those issues which leaders fail to resolve,' to the learners for them to have a clear understanding of the concept. Lastly, the teacher proceeded with elaboration of 'characteristics of leaders'. Learners' responses in their groups also showed that they were developing deeper knowledge of leadership styles. This is evidenced from the fact that they are able to expound on the central ideas 
and concepts they have been assigned to work on. For example, the learners mature responses such as 'when leaders face challenges, they should not give up but they should find solutions to their challenges,' 'the leader should delegate', 'leaders should not give up when they find problems but they should face up the challenges', and 'the leader should encourage his subjects when they face difficulties or when they go through hard times', all show that the learners are developing deeper knowledge on the topic of leadership styles.

Many of the teachers' lessons however showed weakly structured knowledge discourses. Teachers 2, 6 and 9 did not deal with significant concepts and ideas. Teacher 6 mainly explained through learners reading from the learners' textbook. Similarly, Teacher 9 explained through reading information from the Teachers' Guide.

Below, an episode illustrating superficial coverage of knowledge or subject matter taught in the lessons is examined.

Teacher: From yesterday, I have seen that most of you do not understand the meaning of mirroring and so I will continue looking at it again and again. What we have been saying is the definition of mirroring? Who can try, anyone?

Yes?

Learner (Reading from the text book): Mirroring is an activity which someone can copy from somebody.

Teacher: Yes?

Learner: Mirroring is copying from someone

12: 00 Teacher: Yes, that is what we have been saying is the meaning of mirroring. Mirroring is an art of copying an action, words or expressions...

In the above excerpt, the concept of 'mirroring' has been very poorly co-extended. For example, the teacher explains the meaning of the main idea or concept to be covered in the lesson by asking a learner to just read from the textbook. The teacher does define the term 'mirroring' as an act of copying an action, words or expressions but does not elaborate or shed more light on each forms of mirroring and other concepts which have been read by the learner from the textbook.

\subsubsection{Instrumental forms of knowledge}

Generally, 'Instrumental' forms of knowledge were evident in more than half the lessons observed. The excerpt below, from a lesson conducted by Teacher 3 at school 'B,' an urban school, illustrates 'Instrumental' forms of knowledge in the Expressive Arts lessons observed.

The lesson began at 7:30 a.m. There were 41 children present that day. As part of the introduction of the day's Expressive Arts lesson, the teacher formally greeted the learners and began the lesson as follows:

\section{7:30 a.m.}

Teacher: Today we will discuss about songs, about singing. O.k., can you just sing one song that you sing at your homes or here at school that expresses happiness or enjoyment. Sing one song. I want you to sing using soprano, tenor and bass.

(The teacher led the learners in singing the song: We are walking in the light of God, Allelujah, we are walking in the light of God. We are walking in the light of God)

Teacher: We are walking in the light of God Allelujah!

Learners (singing together): We are walking in the light of God. We are walking in the light of God.

Teacher: Have you enjoyed?

Learners (collectively): Yes

Teacher: Thank you for enjoying. Sometimes we need to enjoy.

In the above excerpt, the teacher must be commended for producing 'enjoyment' in the classroom. She is teaching the skills of singing and walking to the beat of the song that reflects what is valued by the local culture. The singing skills are apparently being taught to enable the learners to participate effectively in the social lives of their communities or societies. Teachers were thus observed to be focussing their teaching on those sections of the Expressive Arts curriculum which were on 'ethnic culture' of their communities or societies than intellectual enhancement and development of learners.

\subsubsection{Deep understanding}

Generally, most of the learners demonstrated understanding involving the coverage of everyday knowledge which they 
could easily remember and were able to provide feedback to the teacher, but there was lack of progression to conceptual knowledge that required the learners to do much reasoning, explanations and arguments. The questioning by the teachers in the lessons did not facilitate deep understanding on the part of the learners.

An in-depth analysis of data revealed that $87 \%$ (62 out of 71) of the lessons showed superficial understanding on the part of learners. The 62 lessons showed that the learners did not understand what they were being taught. For example, learners either failed to answer teachers' questions or in cases where they were able to answer their teacher's questions, their responses were mostly one-word answers which were mainly recitation of fragmented pieces of information which did not show understanding of what the learners were learning.

Below, an episode that illustrates learners' superficial understanding is examined.

The lesson began at 10:00 a.m. There were 100 children present in class that day. The teacher was teaching about types of leaders in a community. The teacher progressed with the lesson as follows:

\author{
Teacher: Do you now understand roles of a village head? \\ Learners: No \\ Teacher: Ntchito za amfumu a m'mudzi simukudzimvetsa? (translated as: Is it really true that you do not understand the \\ roles of a village head?) \\ Learner: Mm. \\ Teacher: Ntchito za a mfumu a m'mudzi simukudzimvetsa zowona? (translated as: Are you really serious that you do \\ not understand roles of a village head?) \\ Learner: Mm. \\ Teacher: Kumudzi kwanu nkuti? (translated as: Where do you come from yourselves?) \\ Learner : Lilongwe \\ Teacher: Ku Lilongweko sikukhala a mfumu? Kuli mfumu Mazengera kumenekuja yotchuka. Ndiye mfumu suyidziwa, \\ tiwamvere chisoni eti?(translated as: So there are no village heads in Lilongwe. Do you not know that there is village \\ headman Mazengera there? You should feel ashamed of yourself).
}

The above excerpt shows that the teachers' presentation of the lesson, including questioning did not facilitate deep understanding of the lesson on the part of the learners. For example, teachers' remarks such as, 'Is it really true that you do not understand the roles of a village head?, 'Are you really serious that you do not understand roles of a village head?, and 'You should feel ashamed of yourself', shows that learners seemed to have been unable to answer even those questions which the teacher considered as simple, to the extent that the teacher rebuked and shouted at the learners, thinking that the learners were just being rude to her.

While deep understanding of content knowledge taught was weakly evident in the majority of the lessons observed, there were a few lessons in which the questioning by teachers facilitated deep understanding on the part of the learners.

In 13\% (9 lessons out of 71) of the lessons, teachers' questioning and overall lesson presentation strategies facilitated Deep understanding in the learners. These nine lessons had 10 episodes of Deep understanding, in which the learners responses to a teacher's question showed that the learners were developing relatively systematic, integrated and holistic understanding of concepts they were learning, and the learners were not just reciting fragmented pieces of information.

The episode below, illustrates 'Deep understanding' on the part of the learners about what they were being taught in the lessons:

The lesson began at 8:04 a.m. There were 27 children present in the class. The teacher was teaching about types of leaders in a community. The teacher asked the learners to explain the characteristics of autocratic leadership, to which one of the learners gave the following response:

Learner: There is no second opinion. If the leader says do this, all the people have just to do what their leader tells them to do without opposing that. You cannot even ask questions otherwise you can just face problems.

The above excerpt shows that at least one of the learners is developing a deeper understanding of the subject matter of leadership styles which they are learning. For example, the learner's response to the teacher's task shows that this learner is doing more than just memorizing and citing information; rather this learner is able to reorganize and synthesize the information he got from the teacher into his own complex thoughts, showing that he understood the lesson. 


\title{
5.1.5 Substantive conversation
}

Generally, there was no evidence of substantive conversation in the classroom in the majority of the Expressive Arts lessons observed. There was more teacher talk and there were very limited two-way interactions between learners and between the teachers and the learners. Learners answered in a word or two to the teacher's questions. In-depth analysis of data revealed that $80 \%$ of the lessons were characterised by lack of substantive conversation between the learners and between the teacher and the learners.

The episode below, reconstructed from my field notes of an Expressive Arts lesson conducted by Teacher 2, in Standard 7 at school 'A,' a rural school on the 13th of January, 2010, illustrates lack of substantive conversation in the lesson.

The lesson began at 11:55 a.m. There were 56 children present in the class. The teacher was teaching about garments that convey cultural messages. The teacher progressed with the lesson as follows:

\author{
Teacher: Can you mention some of the garments which can be used to convey cultural messages which we discussed \\ yesterday? \\ Learner: white dress \\ Teacher: What else? \\ Learner: Black garments \\ 12: 00 noon: Teacher: Can you go into your groups and open your Expressive Arts text books on page 10. Can you \\ discuss the materials which were used to make the garments which shown in the pictures on page 10.
}

(I listened to the discussion of one of the groups. One learner said, "chishango are animal hide." Another learner responded, "nyau dance is carton." There were three boys in this group who were not participating in the discussions of the group. The three boys were rather involved in some kind of play which seemed not to have been related to the activity which they had been assigned to work on).

In the above episode, there was little substantive conversation taking place between the learners or between the teacher and the learners. For example, in the entire nine minutes of group discussion in the above excerpt, there were only two responses made by the learners to the task given them. During much of the time, the learners seemed to have been engaged in off-task activities.

Again when responding to the teacher's questions, learners were giving one-word responses. The teacher was not probing further to sustain conversation with the learners.

While substantive conversation was weakly evident in the majority of the lessons, there were a few lessons in which there were more substantive conversations.

Data revealed that substantive conversation was evident in 20\% (14 out of 71 ) of the lessons. These 14 lessons had 14 episodes of substantive conversation.

The episode below, reconstructed from a lesson conducted by Teacher 12 in Standard 8 at school ' $C$,' a rural school on the 15th February, 2010, illustrates 'substantive conversation' in the observed lessons:

8:07 a.m.

Teacher: Now in your group, you can just identify one type of dance. For example, a group can have Beni dance. And another group can have another type of dance. Can you identify those dances? Just one, one dance per group.

(I sat at a group composed of four girls and one boy. The boy told his colleagues 'kandiyandiya' (translated as: It is Kandiyandiya dance). One girl told the group, 'likhuba' (translated as: It is likhuba dance). Another girl asked her colleagues, 'Is a Likhuba a dance? The boy in the group responded, 'ee, ndimayesa ndi dance?' (translated as: Yes, I really thought this is a dance). The girl asked further, 'koma amavina nthawi yanji?' (translated as: But at what time of the day is this dance performed?) The boy answered, 'kaya' (translated as: well, I don't really know). The girl enquired further, 'ndiye iwe sukudziwa?' (translated as: So you don't know as well). Another girl remarked, 'Likhuba dance' (translated as: it is Likhuba dance). The rest of the members of the group agreed with her and they wrote in their note books, 'likhuba' dance.

In the above excerpt, there was substantive conversation taking place amongst the learners for two reasons. Firstly, the learners were asking each other questions which were open-ended and had possibilities of sustaining the conversation amongst them. For example, one learner in the excerpt above remarked that, " "pamenepa likwatayu timuyike question mark chifukwa gule ameneyu akativuta kulongosola kwake chifukwa chakuti sitimadziwa kavinidwe kake ndi nthawi yake imene amavinira. Anzanga mukuganiza bwa, tiyikepo imeneyi?" (translated as: we should put some 
question mark to 'likwata' dance here because we will find it difficult to explain more about the dance because we do not know how the dance is performed, what do you think, should we include this?). This question sustained and extended the conversation amongst the learners as they worked on the learning task. Secondly, each learner in the group was participating actively and making a contribution to sustain the discussion in the group.

\subsubsection{Knowledge as problematic}

There was no evidence of knowledge as problematic. All knowledge was presented as 'given', in an uncritical manner where there was no argumentative discussion on information between learners and teachers; the learners accepted almost all information given by the teachers instantly.

The episode below extracted from a lesson conducted by Teacher 9, in Standard 7 at school 'E,' a rural school on 08th February, 2010 illustrates lack of presentation of knowledge as problematic in the lessons.

8:05 a.m.

Teacher: (Reads for the learners from the Teacher's Guide).

O.K. Different body movements can convey specific messages. For example, a person might wave a hand like this rather than saying hello or nod his or her head in agreement with whatever somebody is saying. The body movements can be useful in expression and communication because they are a big way to convey thoughts and feelings without speaking. There are certain messages to be conveyed and expressed by body movements. These messages are very important in any cultural setting. This is because it enhances cooperation amongst members of the same community. Is this clear?

\section{Learners (collectively): Yes}

The above excerpt shows that the teacher presented knowledge as 'given', in an uncritical manner. The teacher did not create an opportunity for any debate or argument on the information presented to the learners. The teacher conducted a monologue and read the content of the Teacher's Guide to the learners. The above excerpt again illustrates the general practice of most of the teachers in the study that the teachers simply transmitted information to learners and that learners received information passively from their teacher.

\subsubsection{Metalanguage}

Teachers discourse showed little evidence of instruction of metalinguistic concerns. Teachers did not really take into account or give feedback to learners' usage of language. They proceeded with their lessons without alerting learners to their own or learners' use of language. Only Teacher 6 gave guidance to learners' language usage during the lessons.

The episode below, illustrates presentation of metalanguage by only one out of the twelve teachers in the study.

Teacher: The items produced in carving depends on where someone is coming from (code switches: takambapo za carving yomwe imachitika ndi anthu omwe ali pafupi ndi nyanja (translated as: we have been talking about carving which happens in the areas of the lakeshore. Those people along the lakeshore like making carvings of fish. What have I written on the chalkboard on the things which people along the lakeshore like carving? Can you say it? Learners: poultry

Teacher: What? Learners: poultry Teacher: not poultry, but pottery...

In the excerpt above, the teacher corrected the learners' incorrect pronunciation of the word 'pottery', which they were wrongly pronouncing as 'poultry'.

\section{Summary of Intellectual Quality of lessons}

Generally, the observed Expressive Arts lessons are characterised by lower intellectual quality, with the four indicators of high intellectual quality; higher-order thinking, deep-knowledge, deep understanding and substantive conversation being present in only $38.9 \%$ of the observed lessons.

Findings on Intellectual Quality Dimension of Productive Pedagogies found in the 71 lessons are summarized in Table 3 below. 
Table 3: Summary of episodes in the indicators of High Intellectual Quality dimension

\begin{tabular}{|l|c|c|c|c|}
\hline \multicolumn{1}{|c|}{ Dimension } & Indicator 1 & Indicator 2 & Indicator 3 & Indicator 4 \\
\hline High Intellectual Quality & Higher-order thinking & Deep knowledge & Deep understanding & Substantive conversation \\
\hline Episodes in 71 lessons & 14 & 45 & 10 & 14 \\
\hline Percentage of lessons & $39 \%$ & $30 \%$ & $13 \%$ & $20 \%$ \\
\hline
\end{tabular}

\section{Discussion of Findings}

This study found that the lessons lacked high intellectual quality in terms of conceptual development and in-depth coverage of the subject matter thus compromising possibilities for higher-order thinking and deep understanding on the part of the learners. Most of the Expressive Arts teachers did not encourage the learners to think deeper and participate actively during teaching and learning process. There was thus generally no productive and intellectual discussions going on during the teaching and learning process in the majority of Expressive Arts lessons observed.

This result is consistent with other studies on the practice of Productive Pedagogies by teachers. For example, the study confirms what was found by Zohir et al (2010). Zohir et al, in his study of the classroom practice of productive pedagogies of Malaysian Secondary School Geography teachers, found that the level of intellectual quality in the geography classrooms were very low, as students were less involved with higher order thinking skills as most of the teachers did not encourage the students to think deeper and get actively involved during the teaching and learning process. The teachers in Zohir's study were observed to have been asking lower-level questions to the students. Students were observed only to receive information passively from their teachers most of the times.

There are six possible explanations for these findings. These are presented in the following sub-sections.

\subsection{Lack of in-depth specification of subject matter in the curriculum}

The first possible explanation for lower intellectual quality Expressive Arts lessons is lack of in-depth specification of subject matter in the intended curriculum. As the new curriculum in Malawi was drawn from C2005, it has similar flaws to those of C2005. Allais (2007) has noted that C2005 is weak on conceptual coherence and in-depth coverage of content knowledge largely because of integration of content knowledge and lack of prescribed content in the curriculum. Although the new curriculum in Malawi has prescribed content, it lacks specification of content knowledge due to its key design feature of integration of knowledge. Another impact of the design feature of integration of knowledge on teaching is that teachers do not have adequate or in-depth content knowledge of the integrated Learning Areas of the curriculum they are teaching. This finding is consistent with what Naidoo (2005) found about challenges which teachers face in implementing an integrated curriculum in South Africa. In her study on teachers' perceptions of the Integrated Learning Areas for the junior secondary school curriculum of the South African National Curriculum Statement (2002), Naidoo found that the majority of teachers in her study lacked confidence and were not able to teach integrated Learning Areas due to gaps in their own knowledge (of the various disciplines informing the Learning Areas).

\subsection{Use of the deficit model}

The second possible reason for lower quality lessons is that teachers hold a 'deficit' belief about their learners. Postlesson interviews with teachers in this study revealed that the teachers consider their pupils as slow learners and 'empty buckets', and as such, the teachers feel that in such circumstances, they need to 'give' the learners knowledge instead of letting the learners construct their own knowledge on the subject matter they are being taught. This finding is consistent with the findings of Sarangapani's (2003) study of pedagogic practices of teachers in low-income, under-resourced schools in India. Sarangapani (2003) found that teachers in his study held a 'deficit' picture of their learners, and like the present study, the teachers in Sarangapani's study used expository teaching methods to give sufficient knowledge to their learners.

\subsection{Influence of English as language of instruction}

Although teachers used English as a medium of instruction, they often switched to vernacular whenever they noted that learners were not following. When the teacher switched to vernacular, participation of learners increased. The slight improvement in participation of the learners in lesson activities when a teacher switched to vernacular means that the 
English language skills of the learners is a major obstacle affecting the participation of the learners in the lessons. The learners' weak language skills resulted in very limited interactions between the teachers and the students resulting in low quality lessons. This confirms what other researchers in Malawi found about the use of English or local language as a medium of instruction in primary schools. For example, Mkandawire found that students' participation reduced drastically whenever the class teacher switched from a local language to English. Kaphesi (2001) also found that the use of local language in grade five Mathematics class greatly increased students' participation in lesson activities. These significant research findings suggest that the use of English as a medium of class instruction in the Malawi primary school classrooms reduces students' active participation.

\subsection{Inadequate resource provision and poor use of resources}

This study found that teachers seldom used teaching and learning resources for engaging students in lesson activities on the few occasions they used such resources. When they did employ resources such as a piece of cloth and a needle for practising sewing stitches, the use of the resources was by the teacher and for shorter times. The teacher did the sewing and did not give opportunity to the learners to practice the sewing. The general picture was that the teachers failed to use the techniques and lesson activities suggested in the intended Expressive Arts curriculum because of the appalling shortage of teaching and learning resources.

\subsection{Poor constitution of groups for group work activities}

This study found that teachers did not direct the constitution of groups for group work activities. Learners usually formed groups whenever group work activities were called for. As such, some groups were small and others were very large. Similarly, some groups were based on one gender, or mixed, but with apparent gender-skewed patterns. Such kinds of group formations affected active participation because not much interactive process took place among learners in the way productive pedagogy theory proposes. Thus what Parker (2004) proposed that active participatory classroom activities must help students to deliberate in groups, express their opinions of life issues, and make decisions together, generally failed to occur in the twelve classrooms.

\subsection{Teaching for public examinations}

Results of this study showed that teachers were teaching for and to examinations. The possible explanation for this result is that the classes that were used for this study were to sit for public examinations in the year (2010) when this study was being conducted and the following year 2011. Mandatory examinations may therefore have influenced classroom practices of teachers because the state uses grade eight examinations as the only tool for selecting students for secondary school education.

This study's finding support what other authors and researchers, for example Whitaker (1993), have argued that standardised testing forces teachers to teach in a way that will prepare learners for examinations, and this can affect the achievement of the broad goals and objectives of the curriculum.

\section{Conclusion}

This research, framed by Illuminative Evaluation concepts of 'the instructional system' and the 'learning milieu' employed Lingard's et al(2001) concept of Productive Pedagogies to analyse pedagogic practice in twelve Expressive Arts classrooms. Coding of data according to indicators of intellectual quality of lessons resulted in the majority of the lessons being characterised by lower intellectual quality. The overall picture from these findings is that classroom atmosphere in the twelve classrooms gave students limited opportunities for the acquisition of knowledge and development of skills, values and attitudes required for them to actively participate in the changing Malawian context and to be able to compete successfully in other contexts. It appears that dominant pedagogic practices in the Expressive Arts classroom serve to position learners in parochial orientations and issues. Therefore, there was an obvious discrepancy between the state's intended curriculum or the instructional system and the teachers' enacted curriculum or the learning milieu.

The implications of these findings for Malawi education have been raised. The most salient of these implications include the need for Malawi Institute of Education, the main change agent of primary school curriculum in the country, not only to consider revising the Expressive Arts curriculum and providing the resources necessary but also to focus on the development of teachers knowledge of the Learning Areas and pedagogic knowledge so that higher intellectual quality 
lessons are taught. This would expand the practice of productive pedagogies in Expressive Arts classrooms.

\section{References}

Ahmad, Z.S., Zohir, M. \& Razak, N. (2010). Exploring the Clasroom Practice of Productive Pedagogies of the Malaysian Secondary Geography Teacher. Journal of Review of International Geographical Education. Vol.2, No.2, Summer, 2012.

Allais, S. (2007). Education service delivery: the disastrous case of outcomes-based qualifications frameworks. Progress in Development, 7,1:65-78.

Boaler, J.(1997). When even the winners are losers: evaluating the experiences of 'top set' students, Journal of Curriculum Studies, 29(2), pp. 165-182.

Chisholm, L. (2005). The politics of curriculum review and revision in South Africa in regional context. In, Naidoo, D. (2009). Educational Theory and Enquiry 2. Course Reading Pack. Johannesburg: University of the Witwatersrand.

Croft,A.(2002). Singing under a tree: Does oral culture help lower primary teachers be learner-centred? [Electronic version]. International Journal of Educational Development, 22, 321-337. Retrieved, March, 1, 2010 from www.elsevier.com/locate/ijedudev.

Hayes, D., Ladwig, J., Lingard, B., Mills, M., Bahr, M., Chant, D., Warry, M., Ailwood, J., Capeness, R., Christe, P., Gore, J. and Luke, A. (2001). The Queensland school reform longitudinal study, Vol. 1 and 2. Brisbane: Educational Queensland.

Hayes, D., Lingard, B., Mills, M. and Christe, P. (2006). Teachers and Schooling Making a Difference: productive pedagogies, assessment and performance. Sydney: Allen and Unwin.

Ishak, N.A. (2010). Amalan pedagogi produktif dalam guru-guru sains. Unpublished M.Ed Dissertation, School of Educational Studies, Universesiti Sains Malaysia.

Kaphesi, E.S.(2001). The use of language in mathematics teaching in Malawi. Unpublished PhD, University of Nottingham, Nottingham.

Khomani, P. (2005). Implementing the Malawi Primary Curriculum and Assessment Reform. In Curriculum and Assessment Reform for quality education in the $21^{\text {st }}$ Century. Zomba, Malawi Institute of Education.

Lingard, B., Hayes, Ladwig, J., Mills, M., Bahr, M., Chant, D., Warry, M., Ailwood, J., Capeness, R., Christe, P., Gore, J., Hayes, D.\&Luke, A. (2001). The Queensland school reform longitudinal study. Vol.1and 2. Brisbane: Educational Queensland.

Lingard, B. (2007). Pedagogies of indifferences. International Journal of Inclusive Education, 11(3), 245-266.

Mhango, A.C.M. (2010). An exploration of the teaching of Social Studies in primary schools in Malawi. Unpublished PhD Thesis, Virginia Polytechnic Institute and State University, Blacksburg.

Moore, R and Muller, J. (2001). The discourse of 'voice'and the problem of knowledge and identity in the sociology of education: British Journal of Sociology of Education,20, pp.189-206.

Mkandawire, M.T.S.(2004). Attitudes and views on local languages as media of instruction in Malawi.Unpublished Masters, Virginia Polytechnic Institute and State University, Blacksburg.

Naidoo, D. R. (2006). Curriculum, context and identity -an investigation of the curriculum practices of grade 9 teachers in three contrasting social-economic school contexts. Unpublished Doctor of Philosophy Thesis, University of Kwazulu-Natal, Pietermaritzburg.

Parlett, M. and Hamilton, D.(1976). Evaluation as illumination. In Tawney, D.(ed.). Curriculum evaluation today: Trends and implications. London: SCRS.

Parker, W.(2004). Teaching democracy: Unity and diversity in public life. New York: Teacher's College Press.

Sarapangani, A.(2003). Ethnography of Learning in a northern Indian village. International Journal of Educational Development 30(2010)297-304 